DOI:

10.1038/nrg2247

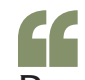

Remarkably, while immuno-

\section{fluorescence} detection of protein has been around since $1949 \ldots$ FISH was not 'fully cooked' until the early 1980s.

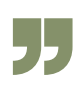

\title{
MILESTONE 3
}

\section{Fully cooked FISH}

Fluorescence in situ hybridization (FISH) has become a methodological mainstay in many fields. It permits the detection, quantification and localization of genes and RNA at resolutions ranging from single nucleotides to whole chromosomes, or even whole cells, using a fluorescently labelled complementary DNA or RNA probe. Remarkably, while immunofluorescence detection of protein has been around since 1949, and immunofluorescent stains for nucleic acids soon followed, FISH was not 'fully cooked' until the early 1980s.

The principal development that led to FISH as we know it today was the determination of the sample fixation and permeabilization conditions necessary to fix cells in their native structure, while allowing the introduction and specific annealing of complementary labelled nucleicacid molecules. A system that would permit easy testing and validation of the methods was also needed.

In the 1960s, Joe Gall and Mary Lou Pardue at Yale University were studying the extrachromosomal amplification of ribosomal RNA genes in Xenopus laevis. This system conveniently provides a known sequence at a high copy number and in an easily identifiable region of the cell. They were able to prepare tritiated complementary RNA of adequate purity and activity to determine the conditions permitting clear visualization of the extrachromosomally amplified ribosomal DNA. They predicted that labelling the RNA at a higher specificity would permit the detection of nonduplicated genes in chromosomes.
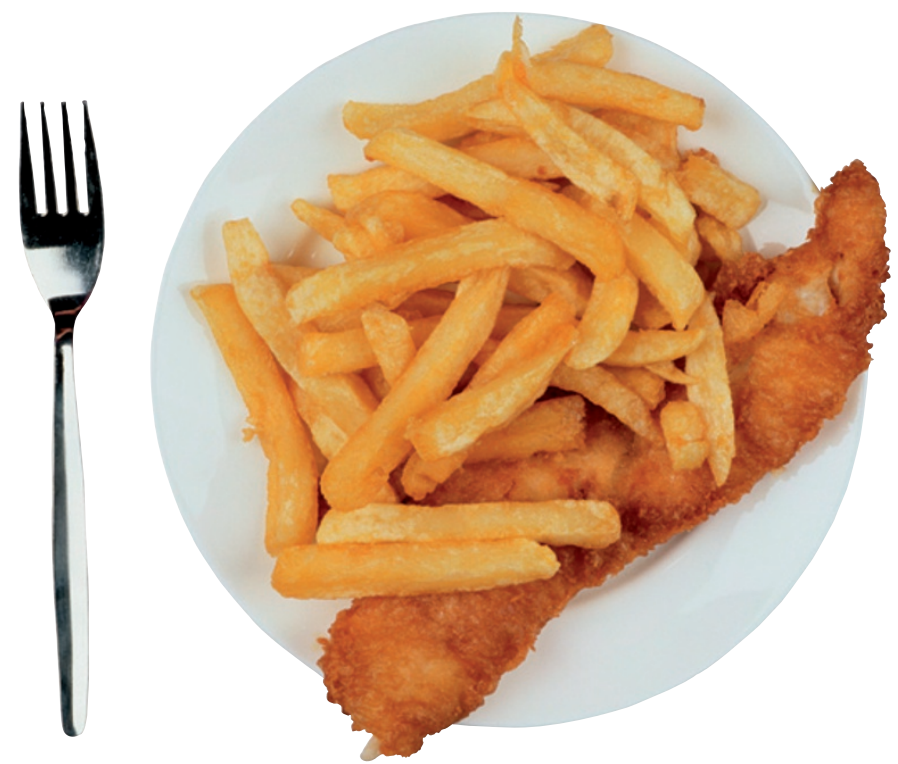

Pardue later went to work with members of the Max Birnstiel laboratory. Using Drosophila melanogaster polytene chromosomes, they could visualize the location of histone genes on individual chromosomes. However, the use of radioactivity, high background levels and long exposure times were problematic, and multiplexing was impossible. It was not long before fluorescently labelled nucleic acids provided the final crucial tool that gave us the sensitive multiplexing versions of FISH we have today.

Two different methods for fluorescently labelling nucleic acids are commonly used for FISH. The 'direct' method, first described by P. van Duijn and colleagues, relies on direct labelling of the nucleic acid with fluorophores and was the first implementation of FISH. The 'indirect' method, developed later by the David Ward group and implemented in commonly used FISH kits, employs immunogenic or enzymatic detection of tagged nucleic-acid probes following hybridization.

As improvements to the 'recipe' continue to be made, FISH is finding its way onto the plate of increasing numbers of researchers and promises to do so for the foreseeable future.

Daniel Evanko, Senior Editor, Nature Methods

ORIGINAL RESEARCH PAPERS Gall, J. G. \& Pardue, M. L. Formation and detection of RNA-DNA hybrid molecules in cytological preparations. Proc. Natl Acad. Sci. USA 63, 378-383 (1969) | Pardue, M. L., Kedes, L. H., Weinberg, E. S. \& Birnstiel, M. L. Localization of sequences coding for histone messenger RNA in the chromosomes of Drosophila melanogaster. Chromosoma 25, 135-151 (1977)| Bauman, J. G., Wiegant, J., Borst, P. \& van Duijn, P. A new method for fluorescence microscopical localization of specific DNA sequences by in situ hybridization of fluorochrome labelled RNA. Exp. Cell. Res. 128, 485-490 (1980) |Langer, P. R., Waldrop, A. A. \& Ward, D. C. Enzymatic synthesis of biotin-labeled polynucleotides: novel nucleic acid affinity probes. Proc. NatlAcad. Sci. USA 78, 6633-6637 (1981) 